\title{
Changes in the composition of phenolic compounds and antioxidant properties of grapevine roots and leaves (Vitis vinifera L.) under continuous of long-term drought stress
}

\author{
A. Król · R. Amarowicz · S. Weidner
}

Received: 3 February 2014/ Accepted: 20 March 2014/Published online: 6 April 2014

(c) The Author(s) 2014. This article is published with open access at Springerlink.com

\begin{abstract}
Grapevine seedlings Vitis vinifera L. were grown in a greenhouse under optimum conditions (soil moisture ca $70 \%$ ) and under drought stress (soil moisture ca $30 \%$ ). Drought stress caused reduction in total phenolic compounds in grapevine leaves and roots, where were identified tree phenolic acids: caffeic acid, $p$-coumaric acid and ferulic acid. All acids found in leaves and roots occurred in the ester-bound form. Only caffeic acid in leaves appeared in the free and ester-bound form. Caffeic acid was present in the highest concentrations. The content of ferulic acid was the lowest in both tissues. The levels of all phenolic acids in leaves and roots decreased significantly under the drought stress. All the extracts from grapevine leaves and roots had antioxidative properties, but the antiradical activity of the extracts obtained from roots subjected to drought stress was lower to the control. The results of the analysis revealed that long-term drought stress caused a decrease in selected elements of secondary metabolism in such a different plant tissues that are the leaves and roots of the grapevine.
\end{abstract}

Keywords Vitis vinifera L. · Antioxidant system · Drought stress · Phenolic compounds · Phenolic acids

Communicated by S. Abe.

A. Król $(\bowtie) \cdot S$. Weidner

Department of Biology and Biotechnology, University of

Warmia and Mazury in Olsztyn, M. Oczapowskiego St. 1A,

10-957 Olsztyn-Kortowo, Poland

e-mail: angelika.krol@uwm.edu.pl

\section{R. Amarowicz}

Division of Food Science, Institute of Animal Reproduction and Food Research of the Polish Academy of Sciences,

Tuwima Street 10, 10-748 Olsztyn, Poland

\section{Introduction}

According to estimated data, a $70 \%$ increase in crop yield could be achieved if the environmental conditions were close to optimum for a given plant. That is why identifying and managing the adverse environmental effects is a top priority in many countries in the world (Chaves and Oliveira 2004). The main factors that restrain the plant distribution are environmental stresses, such as drought, low or high temperature and excessive salinity. These abiotic stress factors generate secondary stresses, i.e. osmotic and oxidative stress, which have negative influence on the plant, causing changes in its normal growth, development and metabolism (Bohenert et al. 1995; Kranner et al. 2010). Thus, it is necessary to conduct research focused on obtaining cultivars, which would be more tolerant to adverse environmental factors. Water stress is one of these environmental factors that can considerably limit distribution of crops in the world (Passioura 2007; Cattivelli et al. 2008; Farooq et al. 2009).

Drought stress decreases water absorption in plants. As a result of membrane phase transition from liquid crystalline structure alters to less liquid jelly structure, selective membrane transport is disturbed (Larcher 1995; Bray 2009). Then in turn, destabilization of nucleic acid structure and alteration of enzyme activity may be observed (Lee et al. 2009; Dumont et al. 2011). A plant's ability to function in the environment, that is continuous source of stress, depends in large extend on their genetic programme (Dodd et al. 2006). Stresses cause the disturbance in cellular redox homoeostasis, which in turn, may lead to secondary oxidative stress and production of reaction oxygen species (ROS) (Asada 2006). ROS fulfil the roles of signalling molecules in order to initiate synthesis of enzyme (catalase, peroxidase, superoxide dismutase) as well as the 
nonenzymatic molecules (glutathione, $\alpha$-tocopherol, carotenoids) that take part in antioxidant reactions. However, during times of environmental stress, ROS levels can increase dramatically. This may result in significant damage to cell structures including nucleic acid and proteins (Smirnof 1993; Aroca et al. 2003; Murata et al. 2012). Consequently, alterations in cellular genetic programming occur. The synthesis of compounds will help create a new homoeostasis (Gilmour et al. 2000). Secondary metabolic products, which are intensively synthesized under drought, are antioxidants (Nascimento and Fett-Neto 2010). This group of compounds protects cells against the negative effects of ROS as well as against lipid peroxidation, protein denaturation and DNA damage (Kranner et al. 2002; Mittler 2002; Allakhverdiev et al. 2008). In turn, environmental stress can cause a decline (Weidner et al. 2007, 2009b) or an increase (Wróbel et al. 2005; Weidner et al. 2009a) in the content of phenolic compounds in a cell. Phenolic compounds can scavenge ROS (Amarowicz et al. 2000, 2004; Negro et al. 2003; Caillet et al. 2006; Amarowicz and Weidner 2009), they form complexes with the metals, which catalyse oxygenation reactions and inhibit activity of oxidizing enzymes (Elavarthi and Martin 2010). Phenolic compounds include many secondary metabolites in plants that exhibit antioxidant properties (Oszmański 1995). Phenols constitute a large group of compounds that may be divided into five subgroups: coumarins, lignins, flavonoids, phenolic acids and tannins (Gumul et al. 2007). Precursors for the synthesis of phenolic compounds are made in the shikimic acid and chorismic acid pathways. The metabolism of chorismic acid leads to L-phenylalanine and L-tyrosine. Tyrosine biosynthesis leads to $p$-coumaric acid and L-phenylalanine synthesis leads to cinnamic acid. As a result of the processes of methylation, hydration and dehydration of cinnamic acid, phenolic acids are produced, as part of the response of the plant to abiotic stresses (Dixon and Paiva 1995). Some of the phenolic compounds, such as phenolic acids or flavonoids, are widely known and present in most of the plant species (Jwa et al. 2006). Phenolic compounds were considered as by-products of metabolic alteration (Solecka 1997). The results investigations unequivocally suggest that phenols not only play a major role in defensive reactions of plants but also influence humans and animals that consume products enriched with phenolic compounds (Franca et al. 2001; Amarowicz and Weidner 2009).

In the literature, the problem of adverse effects on plant growth under the influence of water deficit is often claimed. However, there is little research on the long-term effects of drought on selected elements of secondary metabolism in grapevine leaves and roots.

The aim of the study has been to investigate the quantitative and qualitative modifications of phenolic compounds and to study the antioxidative activity and the reducing power of extracts of grapevine roots and leaves, which occur under long-term drought stress. The main aim of the study was to determine the changes in the content of phenolic acids in the tissues treated with drought.

\section{Materials and methods}

\section{Plant material}

The material for the study consisted of whole root systems and leaves of grapevine Vitis vinifera L., cultivar Kiszmisz Łuczistyj. The seedlings of grapevine for testing were purchased from the company "professional grapevine seedlings" in Józefosław (Poland).

\section{Experimental conditions}

The seedling were transferred into large pots and grown for the next 8 weeks in a greenhouse under optimal conditions (soil moisture ca $70 \%, 25 / 18{ }^{\circ} \mathrm{C}$ day/night cycle and 14-h photoperiod at $180-200 \mu \mathrm{m} \mathrm{m}^{-2} \mathrm{~s}^{-1}$ irradiance). During the whole period, the plants were regularly watered to maintain the optimum soil moisture. The soil moisture was monitored using a VP-PRL-Nr 279462 moisture meter (Mera). When the plants adapted to greenhouse conditions had reached proper size, the experiment began. The seedlings were divided into two groups: control (C) and drought stress $(\mathrm{S})$. The experimental conditions were as follows:

1. Control sample (C) — plants were grown for 2 weeks in optimum conditions established in greenhouses (soil moisture content at the level of about $70 \%$ ). Optimum soil moisture content was guaranteed by systematic watering.

2. Drought stress sample $(\mathrm{S})$ - plants were grown for 2 weeks under drought stress. In the first week, the moisture level was reduced from 70 to $30 \%$ and was maintained at $30 \%$ for the next week. After 2 weeks, both leaf cuttings (only fully developed leaves) and root seedlings (the whole root system) were cut and cleaned from soil by rinsing with room temperature water. Next, all samples were frozen in liquid nitrogen, lyophilized and fragmented in mixer mill. The samples were stored at $-20^{\circ} \mathrm{C}$ until the time of analysis.

\section{Extraction of phenolic compounds}

Phenolic compounds were extracted from plant material three times into $80 \%(\mathrm{v} / \mathrm{v})$ acetone and then three times into $80 \%(\mathrm{v} / \mathrm{v})$ methanol for $15 \mathrm{~min}$ at $80{ }^{\circ} \mathrm{C}$ 
(Amarowicz et al. 2000). Extraction was carried out in a shaking water bath. The solutions from all extractions were combined. After evaporating the organic solvent in a rotary evaporator at $45^{\circ} \mathrm{C}$, the remaining aqueous solution was lyophilized. Finally, the prepared crude extracts were stored at $-20{ }^{\circ} \mathrm{C}$ in the dark until further analysis.

\section{Determination of total phenols}

The content of total phenolic compounds in the extracts was determined using the Folin-Ciocalteu's reagent (Naczk and Shahidi 1989), and (+)-catechin was used as a standard.

Determination of antioxidant activity of extracts by two distinct methods

\section{DPPH radical scavenging activity of the extracts.}

A fresh solution of $\mathrm{DPPH}^{\bullet}$ free radical is purple in colour and reaches maximum absorbance at wavelength $517 \mathrm{~nm}$. The colour of the solution resulting from the presence of free radical disappears under the effect of antioxidative compounds, which extinguish $\mathrm{DPPH}^{\bullet}$. When a free radical is bound to an antioxidant, a colourless product appears. In consequence, the solution becomes colourless and its absorbance is lower.

The antiradical activity was analysed with the method described by Yen and Chen (1995). Briefly, 0.1-0.5 mg of an extract dissolved in $0.1 \mathrm{~cm}^{3}$ of methanol was added to $2 \mathrm{~cm}^{3}$ of methanol; then, $0.25 \mathrm{~cm}^{3}$ of a DPPH (2,2-diphenyl-1-picrylhydrazyl) solution at a concentration of $1 \mathrm{mg} \mathrm{cm}^{-3}$ methanol was added. The mixture was left in the dark at room temperature for $20 \mathrm{~min}$. After that time, absorbance was read at a wavelength of $517 \mathrm{~mm}$. The analysis was performed in three replications.

\section{Trolox equivalent antioxidant capacity (TEAC).}

The antiradical activity also was analysed with the method described by Huang et al. (2005). 0.1-0.5 mg of raw extract was dissolved in $0.1 \mathrm{~cm}^{3}$ methanol, and then $2 \mathrm{~cm}^{3} \mathrm{ABTS}^{+}$radical (2,2'-azinobis(3-ethylbenzthiazoline-6-sulphonic acid) diammonium salt) was added. The mixture was left in the dark at $32{ }^{\circ} \mathrm{C}$ for $20 \mathrm{~min}$. After incubation, the absorption was quantified at $734 \mathrm{~nm}$. Determination of the calibration curve was obtained with Trolox as a standard. A colour solution of $\mathrm{ABTS}^{+\bullet}$ becomes colourless when sample has been added to it. The rate at which the solution loses its colour depends on the amount of added extract and its free radical scavenging activity.
Determination of the reducing power of extract

Reducing power of extracts was measured using the FRAP method (ferric ion reducing antioxidant power) described by Benzie and Strain (1999). 0.1-0.5 mg of raw extract was dissolved in $0.1 \mathrm{~cm}^{3}$ water, and then $3 \mathrm{~cm}^{3}$ FRAP reagent was added (acetic acid buffer of $\mathrm{pH} 3.6 \mathrm{TPTZ}$ (2,4,6-tris(2-pyridyl)-s-triazine). After incubation, the absorption was quantified at $593 \mathrm{~nm}$. Determination of the calibration curve was obtained with Trolox as a standard.

Separation and identification of free, ester-bound and glycoside-bound phenolic acids

Phenolic acids (free and those liberated from soluble esters and from soluble glycosides) were isolated from the extracts according to the method previously described by Zadernowski and Kozłowska (1983) and modified by Weidner et al. (2000). An aqueous suspension of the methanolic extract (400 $\mathrm{mg}$ in $10 \mathrm{~cm}^{3}$ ) was adjusted to $\mathrm{pH}$ 2 with $6 \mathrm{M} \mathrm{HCl}$, and free phenolic acids were extracted five times into $10 \mathrm{~cm}^{3}$ diethyl ether using a separatory funnel. The ether extract was evaporated to dryness under vacuum at room temperature. The water solution was neutralized and then lyophilized. The residue was dissolved in $10 \mathrm{~cm}^{3}$ of $2 \mathrm{M} \mathrm{NaOH}$ and hydrolysed for $3.5 \mathrm{~h}$ under a nitrogen atmosphere at room temperature. After acidification to $\mathrm{pH} 2$ using $6 \mathrm{M} \mathrm{HCl}$, phenolic acids released from soluble esters were extracted from the hydrolysate five times into $15 \mathrm{~cm}^{3}$ diethyl ether. $9 \mathrm{~cm}^{3}$ of $6 \mathrm{M} \mathrm{HCl}$ was added to the water solution, which was then placed in nitrogen atmosphere and hydrolysed for $1 \mathrm{~h}$ at $100{ }^{\circ} \mathrm{C}$. Phenolic acids released from soluble glycosides were separated from the hydrolysate five times into $20 \mathrm{~cm}^{3}$ diethyl ether. After ether evaporation, the dry residue was dissolved in $2 \mathrm{ml}$ methanol and filtered through a $0.45-\mu \mathrm{m}$ nylon filter. The sample was injected onto an HPLC column. A Shimadzu HPLC system was employed: LC10ADVP pump, photodiode array detector UV-VIS SPDM10AVP, oven CTO-10ASVP, controller SCL-10AVP. The conditions of the separations were as follows: prepacked LUNA $\mathrm{C}_{18}$ column $(5 \mu \mathrm{m}, 4.6 \times 250 \mathrm{~mm}$; Phenomenex); mobile phase water-acetonitrile-acetic acid (88:10:2, v/v/v) (Amarowicz and Weidner 2001); flow rate of $1 \mathrm{~cm}^{3} \mathrm{~min}^{-1}$; injection volume of $20 \mu \mathrm{l}$; the detector was set at 280 and $320 \mathrm{~nm}$; oven temperature was $20^{\circ} \mathrm{C}$.

Statistical analysis

All experiments were repeated four times. The results are reported as the mean \pm SD. Statistically significant differences between the mean values were tested by Student's $t$ test. 


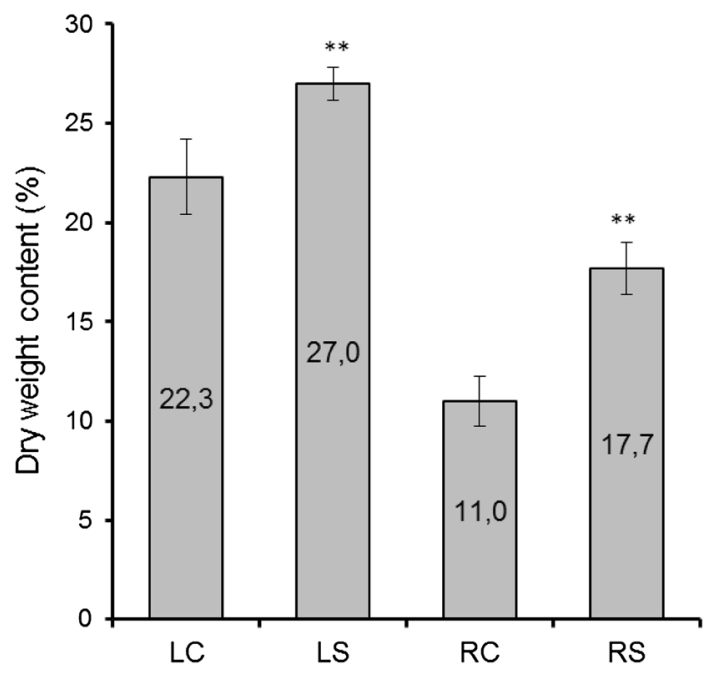

Fig. 1 Percentage content of dry matter in control and drought stressed samples leaves (LC, LS) and roots (RC, RS) of $V$. vinifera. The experimental conditions are explained in "Materials and methods". The vertical lines mark standard deviation $(n=4)$. The asterisks designate significant differences for dependent samples at $p<0.01$ (double asterisks)

\section{Results}

Dry matter content

The changes of percentage dry matter in grapevine leaves and roots are illustrated in Fig. 1. Grapevine leaves (both LC and LS) have significantly higher dry matter content than grapevine roots (RC and RS). The results show that dry matter in leaves of grapevine seedlings subjected to drought stress (LS) was significantly higher $(26.24 \%)$ compared to the control samples of leaves (LC), in which the dry matter content was at the level of $22.31 \%$ (Fig. 1). The same trend was noted in roots, where the dry matter of the stress samples of roots (RS) content was at the level of $17.74 \%$ and was significantly higher than in control samples (RC) (10.98\%).

\section{Content of phenolic compounds}

In Table 1 are reported content of phenolic compounds of all samples recalculated per gram fresh matter, dry matter of tissues and per mg of extract. The results show also that leaves have a lower content of phenolic compounds than roots. Moreover, the content of total phenolic compounds in the samples of leaves and roots subjected to drought stress was lower than in the control samples. The total phenolic compounds in grapevine leaves after drought stress (LS) were significantly lower according to several calculations (272 $\mathrm{mg} \mathrm{g}^{-1}$ of the extract, $62 \mathrm{mg} \mathrm{g}^{-1}$ of the dry matter,
Table 1 Content of total phenolic compounds in control and drought stressed samples leaves (LC, LS) and roots (RC, RS) of $V$. vinifera

\begin{tabular}{llll}
\hline Sample & $\mathrm{mg} \mathrm{g}^{-1}$ of extract & $\mathrm{mg} \mathrm{g}^{-1} \mathrm{DW}$ & $\mathrm{mg} \mathrm{g}^{-1} \mathrm{FW}$ \\
\hline LC & $389 \pm 17$ & $80.4 \pm 8$ & $19.37 \pm 1.47$ \\
LS & $272 \pm 13^{* *}$ & $62.7 \pm 5.59^{* * * *}$ & $15.94 \pm 1.38^{* *}$ \\
RC & $944 \pm 12$ & $286 \pm 18$ & $39.22 \pm 2.73$ \\
RS & $861 \pm 16^{* *}$ & $222 \pm 10^{* *}$ & $27.63 \pm 1.09 * * *$ \\
\hline
\end{tabular}

The experimental conditions are explained in "Materials and methods"

The vertical lines mark standard deviation $(n=4)$

The asterisks designate significant differences for dependent samples at $p<0.01(* *)$ and $p<0.001(* * *)$

$16 \mathrm{mg} \mathrm{g}^{-1}$ of the fresh matter) versus the control sample (LC) (respectively-389 $\mathrm{mg} \mathrm{g}^{-1}$ extract, $80 \mathrm{mg} \mathrm{g}^{-1}$ dry matter, $19 \mathrm{mg} \mathrm{g}^{-1}$ fresh matter).The total phenolic compounds in grapevine roots after drought stress (RS) were significantly lower according to several calculations (891 $\mathrm{mg} \mathrm{g}^{-1}$ of the extract, $222 \mathrm{mg} \mathrm{g}^{-1}$ of the dry matter, $27 \mathrm{mg} \mathrm{g}^{-1}$ of the fresh matter) versus the control sample (RC) (respectively: $944 \mathrm{mg} \mathrm{g}^{-1}$ extract, $268 \mathrm{mg} \mathrm{g}^{-1}$ dry matter, $39 \mathrm{mg} \mathrm{g}^{-1}$ fresh matter).

The $\mathrm{DPPH}^{\bullet}$ scavenging activity of extracts

Extracts of all the samples demonstrated DPPH ${ }^{\bullet}$ scavenging activity, which suggests that they all contained antioxidants. The samples possessing the highest antioxidant activity were characterized by the lowest absorbance (Fig. 2).

At the highest extract concentration $(0.5 \mathrm{mg} / \mathrm{sample})$ in control samples of leave (LC), the absorbance was at the level of 0.34 and it was significantly lower that stress sample of leaves (LS) (0.42). However, at the highest extract concentration in control sample of roots (RC) $(0.05 \mathrm{mg} / \mathrm{sample})$, the absorbance was 0.14 . In the same extract concentration from stress sample of roots (RS), the absorbance was at the level of 0.19 . Between these samples are significant differences. Results of revealed that control samples of leaves and roots were a higher antioxidant activity than stress samples. The highest capacity to scavenge $\mathrm{DPPH}^{\bullet}$ was seen in the extract from roots.

\section{Trolox equivalent antioxidant capacity (TEAC)}

The $\mathrm{ABTS}^{+\bullet}$ scavenging activity is illustrated in Fig. 3. The results showing the antioxidative activity of the extracts have been presented as Trolox equivalents.

The results confirm that all the analysed samples were able to scavenge ABTS free cation radical. Moreover, control sample and stressed samples of roots had more the $\mathrm{ABTS}^{+\bullet}$ free radical scavenging activity compared to 

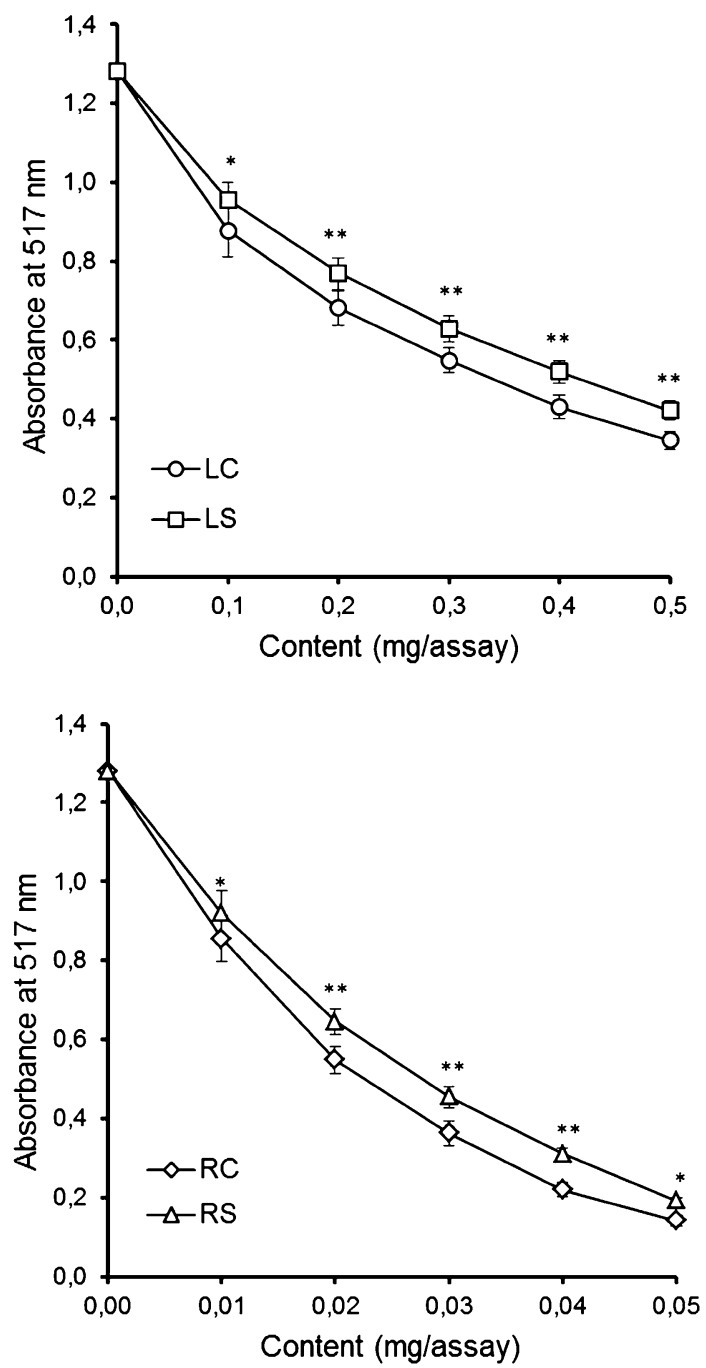

Fig. $2 \mathrm{DPPH}^{\bullet}$ free radical scavenging activity of extracts from control and drought stressed samples leaves (LC, LS) and roots (RC, $\mathrm{RS})$ of $V$. vinifera. The experimental conditions are explained in "Materials and methods". The vertical lines mark standard deviation $(n=4)$. The asterisks designate significant differences for dependent samples at $p<0.05$ (single asterisks), at $p<0.01$ (double asterisks)

control and stressed samples of leaves. Analogously to the tests on $\mathrm{DPPH}^{\bullet}$ scavenging activity, described above, the samples of leaves (LS) subjected drought stress (LS) showed a significantly lower free radical scavenging activity than the control sample of leaves (LC): respectively $0.33 \mathrm{mmol}$ Trolox $\mathrm{g}^{-1}$ extract (LS) and $0.42 \mathrm{mmol}$ Trolox $\mathrm{g}^{-1}$ extract (LC). The same relationship was observed in the case of the roots where the able to scavenge $\mathrm{ABTS}^{+\bullet}$ free cation radical of stress sample (RS) was significantly lower than control sample (RC): respectively $1.07 \mathrm{mmol}$ Trolox $\mathrm{g}^{-1}$ extract from RS and $1.25 \mathrm{mmol}$ Trolox $\mathrm{g}^{-1}$ extract from RC. These results indicate that control sample of leaves and roots had more the ABTS free radical scavenging activity, compared to the stress samples.

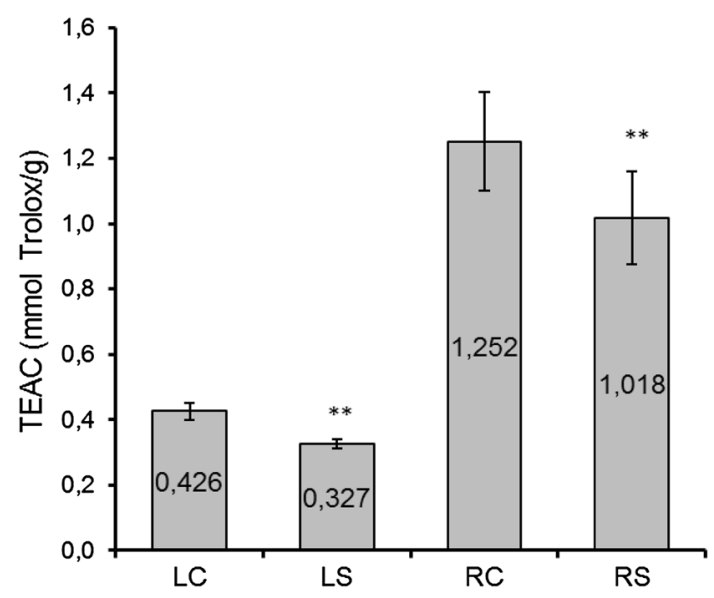

Fig. $3 \mathrm{ABTS}^{+}$free cation radical scavenging activity of extracts from control and drought stressed samples leaves (LC, LS) and roots (RC, RS) of $V$. vinifera. The experimental conditions are explained in "Materials and methods". The vertical lines mark standard deviation $(n=4)$. The asterisks designate significant differences for dependent samples at $p<0.01$ (double asterisks)

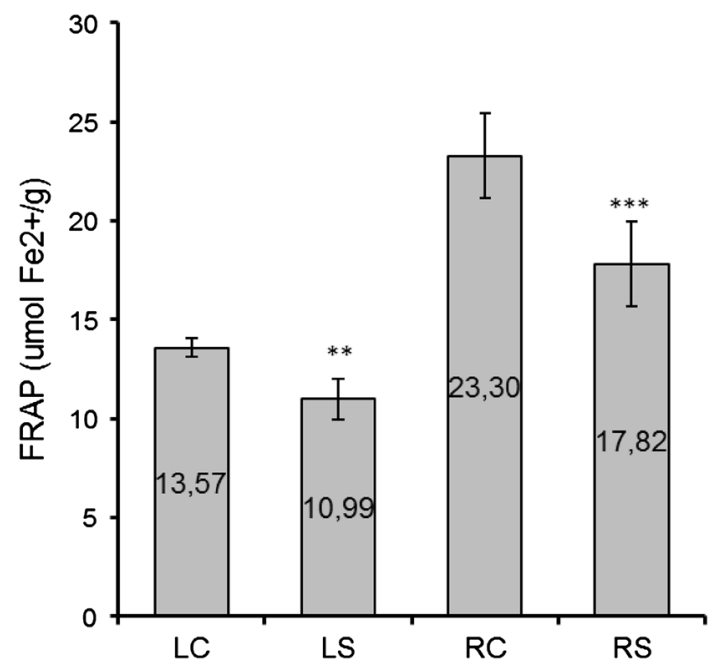

Fig. 4 Reducing power of extract from control and drought stressed samples leaves (LC, LS) and roots (RC, RS) of V. vinifera. The experimental conditions are explained in Table 1. The vertical lines mark standard deviation $(n=4)$. The asterisks designate significant differences for dependent samples at $p<0.01$ (double asterisks), at $p<0.001$ (triple asterisks)

Determination of the reducing power of extract

Determination of the reducing power of extract in leaves and roots grapevine is illustrated in Fig. 4. Under the influence of the reducing power of the extracts, $\mathrm{Fe}^{3+}$ ions were reduced to $\mathrm{Fe}^{2+}$ ions, and the colour of the mixture changed from light orange blue to dark blue. The results confirm that all the analysed samples were able to reduce $\mathrm{Fe}^{3+}$ ions. It was shown that control sample of leaves and roots were more 
capable of reducing $\mathrm{Fe}^{3+}$ ions, compared to the stress sample. The samples of leaves (LS) subjected drought stress showed a significantly lower reducing power than the control samples of leaves (LC), respectively, $10.99 \mathrm{mmol}$ Trol$\mathrm{ox} \mathrm{g}^{-1}$ extract (LS) and $13.56 \mathrm{mmol}$ Trolox $\mathrm{g}^{-1}$ extract (LC). The same relationship was observed in the case of the roots where the reducing power ability of the stressed samples (RS) was significantly lower than control samples (RC), respectively, $17.81 \mathrm{mmol}$ Trolox $\mathrm{g}^{-1}$ extract from RS and 23.3 mmol Trolox $\mathrm{g}^{-1}$ extract from RC.

\section{Content of phenolic acids}

The assays performed on extracts from grapevine leaves and roots demonstrated that they contained $p$-coumaric, ferulic and caffeic acids. All these phenolic acids appeared in the leaves and roots were in the ester-bound form. Free and glycoside-bound forms of phenolic acids were not also detected in roots and leaves samples. Control and stressed samples of leaves were additionally identified free form of caffeic acid. Among the analysed samples (Figs. 5, 6, 7), ester-bound form of caffeic acid had the highest concentration- in sample of leaves from 5.225 (LS) to $8.03 \mu \mathrm{g} \mathrm{g}^{-1}$ fresh matter (LC) and in sample of roots from 0.412 (RS) to $0.534 \mu \mathrm{g} \mathrm{g}^{-1}$ fresh matter (RC). The free form of caffeic acid had significant lower concentration in control sample of leaves $\left(0.195 \mu \mathrm{g} \mathrm{g}^{-1}\right.$ fresh matter) and stress samples of leaves $\left(0.08 \mu \mathrm{g} \mathrm{g}^{-1}\right.$ fresh matter). The next most abundant compound was $p$-coumaric acid, whose content in leaves was from 0.285 (LS) to $0.309 \mu \mathrm{g} \mathrm{g}^{-1}$ fresh matter (LC) and in roots was from 0.1045 (RS) to $0,1375 \mu \mathrm{g} \mathrm{g}^{-1}$ fresh matter (RC). The content of ferulic acid in all samples was

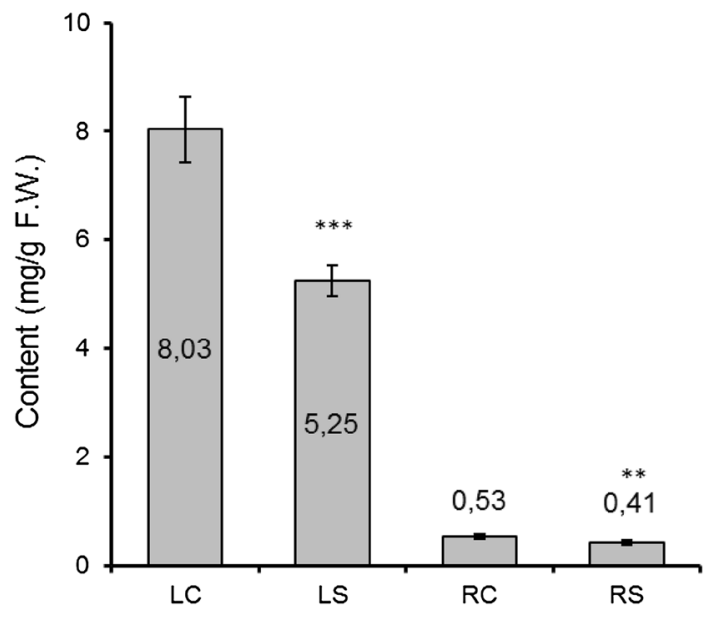

Fig. 5 Content of ester-bound form of caffeic acid in control and drought stressed samples leaves (LC, LS) and roots (RC, RS) of $V$. vinifera. The experimental conditions are explained in Table 1 . The vertical lines mark standard deviation $(n=4)$. The asterisks designate significant differences for dependent samples at $p<0.01$ (double asterisks), at $p<0.001$ (triple asterisks)

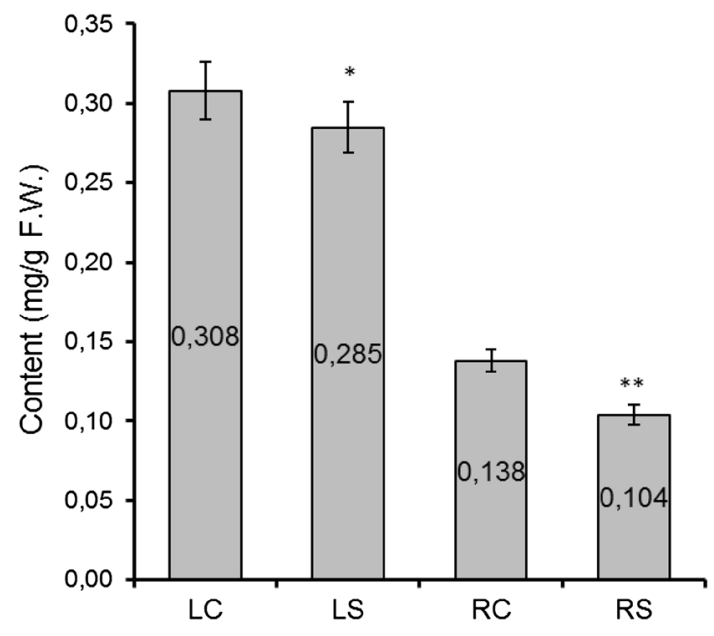

Fig. 6 Content of ester-bound form of $p$-coumaric in control and drought stressed samples leaves (LC, LS) and roots (RC, RS) of $V$. vinifera. The experimental conditions are explained in Table 1 . The vertical lines mark standard deviation $(n=4)$. The asterisks designate significant differences for dependent samples at $p<0.05$ (single asterisks), at $p<0.01$ (double asterisks)

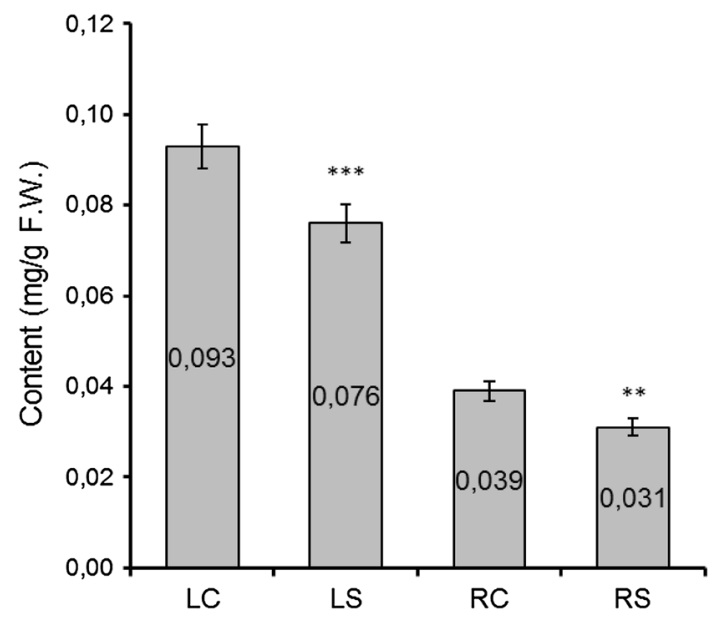

Fig. 7 Content of ester-bound form of ferulic acid in control and drought stressed samples leaves (LC, LS) and roots (RC, RS) of $V$. vinifera. The experimental conditions are explained in Table 1 . The vertical lines mark standard deviation $(n=4)$. The asterisks designate significant differences for dependent samples at $p<0.01$ (double asterisks), at $p<0.01$ (triple asterisks)

the lowest of all identified acids. In grapevine leaves, it varied from 0.076 (LS) to $0.093 \mu \mathrm{g} \mathrm{g}^{-1}$ fresh matter (LC). In roots it varied from 0.0305 (RS) to $0.0385 \mu \mathrm{g} \mathrm{g}^{-1}$ fresh matter (RC). Indeed, the content of all acids in the sample subjected to drought stress (LS, RS) dropped significantly compared to the control sample (LC, RC).

\section{Discussion}

Long-term and continuous drought stress inhibits the total synthesis of phenolic compounds in leaves and roots. 
Similar results were obtained in earlier research on seedlings of $V$. vinifera exposed to chilling stress. The total content of phenolics, tannins and phenolic acids in stress sample was lower than in control sample (Weidner et al. 2009b). Furthermore, Amarowicz et al. (2010) observed the same trend in leaves of $V$. vinifera subjected to lowtemperature stress. On the other hand, some researchers have observed quite the opposite effect. Chung et al. (2006) found out that chilling stress and water deficit caused an increase in the total content of phenolic compounds in Rehmannia glutinosa. These results were confirmed in seedling of soybean subjected to chilling stress (Posmyk et al. 2005). Other experiments have demonstrated that chilling stress did not have any major effect on the total content of phenolic compounds in pea roots, but it significantly decreased the content of flavone (Rudikowskaya et al. 2008). Many authors demonstrated that the production of phenols in plant tissues rises under abiotic stress conditions (Dixon and Paiva 1995; Janas et al. 2002; Wróbel et al. 2005; Weidner et al. 2009a). Such large discrepancies in experimental results can be attributed to differences in abiotic stresses, e.g. type of stress, its intensity, its duration, the stages of plant development (in general, the early stages of germination and plant development are the least tolerant to stress) and the biological material, e.g. whole seedlings or different parts of plants, such as roots or leaves, which are characterized by a great diversity of secondary metabolites (Weidner et al. 2009a).

In response to changing environmental conditions, plants evolved the capacity to biosynthesize different phenolic acids (Cooper-Driver and Bhattacharya 1998; Bieza and Lois 2001; Caldwell et al. 2007). In the present study, three phenolic acids were identified in $V$. vinifera leaves and roots: caffeic, $p$-coumaric and ferulic. The most abundant was caffeic acid, while ferulic acid was the least abundant. All phenolic acids were present as ester-bounds form. Only caffeic acid in leaves appeared in the free form. Under long-term drought stress condition, the level all identified phenolic acids in leaves and roots were reduced. Similar results were shown by Weidner et al. (2011) in germinating seeds of Vitis californica subjected to osmotic stress, but the ester-bound form of caffeic acid increased under stress conditions. In leaves of $V$. vinifera exposed to low temperature, the content of ester- and glycoside-bound caffeic and ferulic acid rose, while that of $p$-coumaric acid declined (Amarowicz et al. 2010). In addition, depressed levels of the ester-bound form of $p$-coumaric, ferulic and caffeic acids have also been observed in roots of $V$. vinifera exposed to chilling stress. $p$-Coumaric acid was the most abundant and caffeic acid the least abundant phenolic in tissues of such roots (Weidner et al. 2009b). Solecka (1997) claims that the presence of larger concentrations of phenolic acids in ester- or glycoside-bound forms in tissues is less toxic to plants, than the free forms. Worth noticing is the fact that the post-stress recovery process caused an increase in the content of the free and ester-bound forms of caffeic and $p$-coumaric acids in germinating seeds of $V$. californica. Also, an increase in the content of ester-bound gallic acid, accompanied by a decrease in its free form, was observed. The post-stress recovery process decreased the ester-bound form of ferulic acid (Weidner et al. 2011). Increased concentrations of ester-bound forms of $p$-coumaric, caffeic and ferulic acids during recovery from chilling stress had been previously detected in roots of $V$. vinifera (Weidner et al. 2009b). Ferulic acid and $p$-coumaric acid are characterized by the highest reducing power of free radicals (Szwajgier et al. 2005).

Antioxidant and antiradical activity of leaves and roots extracts of $V$. vinifera was investigated using several methods such as $\mathrm{ABTS}^{+\bullet}$, scavenging $\mathrm{DPPH}^{\bullet}$ radical and the FRAP assay. The above results suggest that all the extracts from grapevine leaves and roots had antioxidative properties. All extracts from leaves and roots growing under optimum conditions proved to be more efficient in scavenging $\mathrm{DPPH}^{\bullet}$ free radicals and had a higher reducing power than extracts from tissues exposed to drought stress. This finding provides evidence that tissues of grapevine seedlings subjected to stress contain less antioxidants and reducing compounds. Zainol et al. (2003) showed that the phenolic compounds are the major contributors to the antioxidative activities. The extent of antioxidative effects produced by phenols largely depends on the structure of given compound and especially on the number and distribution of hydroxyl groups $(-\mathrm{OH})$. Antioxidative activity is much higher when a compound has two -OH groups in the ortho position (e.g. caffeic acid) (Rosicka-Kaczmarek 2004). Our study also showed that the roots of the grapevine contain more antioxidants than the leaves. There appears to be a significant correlation between the content of total phenolics and antioxidant activity. Xu et al. (2010) claimed the same effect in experiments on different grape cultivars. Similar results were presented in our earlier work (Amarowicz and Weidner 2009) and by Alonso et al. (2002).

When stresses act upon plants, changes in gene expression take place. Within the first $12 \mathrm{~h}$, the expression of many genes is increased (Kilian et al. 2007). It should be noted that this process requires a lot of energy input. But when the stress lasts a long time, the energy-intensive processes are limited. Kilian et al. (2007) claimed that after $24 \mathrm{~h}$, the expression of a large number of genes was inhibited or significantly reduced. Xiong et al. (2006) demonstrated that during long periods of drought stress is a significant decrease in activity of phenylalanine ammonialyase (PAL) in Arabidopsis thaliana roots. PAL (E.C.4.3.1.5) is the main enzyme in the synthesis pathway of phenolic compounds in plants (Szafrańska et al. 2002). 
Numerous studies have revealed that environmental stress often raise the accumulation of phenolic compounds and phenolic acids. It should be noted that most of the studies are concentrated on short-term stress. However, the mechanism of plant response to long and continuous stressor is different. Also the research presented in this paper has demonstrated that the total content of phenolics, phenolic acids and antioxidant activity and reducing power decrease in grapevine leaves and roots under long-term drought stress. It indicates a slowdown in selected elements of secondary metabolism in plants during long-term drought stress. So, the plant reduces energy expenditure until the end of the activity stressor. This is one of strategy for survival in disadvantaged environment conditions.

Author contribution The maintainers of the creation of the manuscript: Professor Stanisław Weidner was: author of research concept and design, critical revision of article, final approval of article. Professor Ryszard Amarowicz was in charge of: critical revision and final approval of article, made measurement of phenolic acids content using HPLC system. Angelika Król was in charge of: collection analysis, data analysis and interpretation, writing the article.

Acknowledgments We thank Profesor Eric Davies, North Carolina State University for reading the manuscript and his valuable comments.

Open Access This article is distributed under the terms of the Creative Commons Attribution License which permits any use, distribution, and reproduction in any medium, provided the original author(s) and the source are credited.

\section{References}

Allakhverdiev SI, Kreslavski VD, Klimov VV, Los DA, Carpentier R, Mohanty P (2008) Heat stress: an overview of molecular responses in photosynthesis. Photosynth Res 98:541-550

Alonso AM, Guillen DA, Barroso CG, Puertas B, Garcia A (2002) Determination of antioxidant activity of wine by products and its correlation with polyphenolic content. J Agric Food Chem 50:5832-5836

Amarowicz R, Weidner S (2001) Content of phenolic acids in rye caryopses determined using DAD-HPLC method. Czech J Food Sci 19:201-205

Amarowicz R, Weidner S (2009) Biological activity of grapevine phenolic compounds. In: Roubelakis-Angelakis KA (ed) Grapevine molecular physiology and biotechnology, 2nd edn. Springer, New York, pp 389-405. doi:10.1007/978-90-481-2305-6_14

Amarowicz R, Naczk M, Zadernowski R, Shahid F (2000) Antioxid ant activity of condensed tannins of beach pea, canola hulls, evening primrose, and fababeans. J Food Lipids 7:199-211

Amarowicz R, Pegg RB, Rahimi-Moghaddam P, Barl B, Weil JA (2004) Free-radical scavenging capacity and antioxidant activity of selected plant species from the Canadian prairies. Food Chem 84:551-562

Amarowicz R, Weidner S, Wojtowicz I, Karmać M, Kosińska A, Rybarczyk A (2010) Influence of low-temperature stress on changes in the composition of grapevine leaf phenolic compounds and their antioxidant properties. Funct Plant Sci Biotechnol 4:90-96

Aroca R, Irigoyen J, Sanchez-Diaz M (2003) Drought enhances maize chilling tolerance. II. Photosynthetic traits and protective mechanisms against oxidative stress. Physiol Plant 117:540-549

Asada K (2006) Production and scavenging of reactive oxygen species in chloroplasts and their functions. Plant Physiol 141:391-396

Benzie FF, Strain JJ (1999) Ferric reducing/antioxidant power assay: direct measure of total antioxidant activity of biological fluids and modified version for simultaneous measurement of total antioxidant power and ascorbic acid concentration. Methods Enzymol 299:15-23

Bieza K, Lois R (2001) An Arabidopsis mutant tolerant to lethal ultraviolet-B levels shows constitutively elevated accumulation of flavonoids and other phenolics. Plant Physiol 126:1105-1115

Bohenert HJ, Nelson DE, Jensen RG (1995) Adaptation to environmental stresses. Plant Cell 7:1099-1111

Bray EA (2009) Genes commonly regulated by water-deficit stress in Arabidopsis thaliana. J Exp Bot 55(407):2331-2341

Caillet S, Salmieri S, Lacriox M (2006) Evaluation of free radicalscavenging properties of commercial grape phenol extracts by a fast colorimetric method. Food Chem 95:1-8

Caldwell MM, Bornman JF, Ballaré CL, Flint SD, Kulandaivelu G (2007) Terrestrial ecosystems, increased solar ultraviolet radiation, and interactions with other climate change factors. Pchotochem Photobiol Sci 6:252-266

Cattivelli L, Rizza F, Badeck F-W, Mazzucotelli E, Mastrangelo AM, Francia E, Marè C, Tondelli A, Stanca AT (2008) Drought tolerance improvement in crop plants: an integrated view from breeding to genomics. Field Crop Res 105:1-14

Chaves MM, Oliveira MM (2004) Mechanisms underlying plant resilience to water deficits: prospects for water-saving agriculture. J Exp Bot 55:2365-2384

Chung IM, Kim JJ, Lim JD, Yu CY, Kim SH, Hahn SJ (2006) Comparison of resveratrol, SOD activity, phenolic compounds and free amino acid in Rehmannia glutinose under temperature and water stress. Environ Exp Bot 56:44-53

Cooper-Driver GA, Bhattacharya M (1998) Role of phenolics in plant evolution. Phytochemistry 49:1165-1174

Dixon RA, Paiva NL (1995) Stress-induced phenylpropanoid metabolism. Plant Cell 7:1085-1097

Dodd AN, Jakobsen MK, Baker AJ, Telezerow A, Hos SW, Laplaze L, Barrot L, Poething RS, Haselhoff J, Webb AAR (2006) Time of day modulates low-temperature $\mathrm{Ca}^{2+}$ signals in Arabidopsis. Plant J 48:962-973

Dumont E, Bahraman N, Goulase E, Valot B, Sellier H, Hilbert JL, Vuylsteker C, Lejeune-Henaut I, Delbreil B (2011) A proteomic approach to decipher chilling response from cold acclimation in pea (Pisum sativum L.). Plant Sci 180:86-98

Elavarthi S, Martin B (2010) Spectrophotometric assays for antioxidant enzymes in plants. Methods Mol Biol 639:273-281

Farooq M, Kobayashi N, Wahid A, Ito O, Basra SMA (2009) Strategies for producing more rice with less water. Adv Agron 101:352-388

Franca SC, Roberto PG, Marins MA, Puga RD, Rodrigeuz A, Pereira JO (2001) Biosynthesis of secondary metabolites in sugarcane. Gen Mol Biol 24:243-250

Gilmour SJ, Sebolt AM, Salazar MP, Everard JD, Thomashow MF (2000) Overexpression of the Arabidopsis CBF3 transcriptional activator mimics multiple biochemical changes associated with cold acclimation. Plant Physiol 124:1854-1865

Gumul D, Korus J, Achremowicz B (2007) The influence of extrusion on the content of polyphenols and antioxidant/antiradical activity of rye grains (Secale cereal L.). Acta Sci Pol 6:103-111

Huang D, Ou B, Prior DL (2005) The chemistry behind antioxidant capacity assays. J Agric Food Chem 53(6):1841-1856 
Janas KM, Cvikrova M, Pałągiewicz A, Szafrańska K, Posmyk MM (2002) Constitutive elevated accumulation of phenylpropanoids in soybean roots at low temperature. Plant Sci 163:369-373

Jwa N-S, Agrawal GK, Tomogami S, Yonekura M, Han O, Iwahashi H, Rakwal R (2006) Role of defence/stress-related marker genes, proteins, and secondary metabolites in defining rice self defence mechanisms. Plant Physiol Biochem 44:261-273

Kilian J, Whitehead D, Horak J, Wanke D, Weinl S, Batistic O, D'Angelo C, Bornberg-Bauer E, Kudla J, Harter K (2007) The AtGenExpress global stress expression data set: protocols, evolution and model data analysis of UV-B light, drought and cold stress responses. Plant J 50:347-363

Kranner I, Beckett RP, Wornik S, Zorn M, Pfeifhofer HW (2002) Revival of a resurrection plant correlates with its antioxidant status. Plant J 31:13-24

Kranner I, Minibayeva FV, Backett RP, Seal CE (2010) What is stress? Concepts, definitions and applications in seed science. New Phytol 188:655-673

Larcher W (1995) Gas exchange in plants. In: Larcher W (ed) Physiological plant ecology, 3rd edn. Springer, Berlin, pp 74-128

Lee DG, Ahsan N, Lee SH, Lee JJ, Bahk JD, Kang KY (2009) Chilling stress-induced proteomic changes in rice roots. J Plant Physiol 166:1-11

Mittler R (2002) Oxidative stress, antioxidants and stress tolerance. Trends Plant Sci 7:405-410

Murata N, Allakhverdiev SI, Nishiyama Y (2012) The mechanism of photoinhibition in vivo: re-evaluation of the roles of catalase, $\alpha$ tocopherol, non-photochemical quenching, and electron transport. Biochim Biophys Acta 1817(8):1127-1133

Naczk M, Shahidi F (1989) The effect of methanol-ammonia-water treatment on the content of phenolic acids of canola. Food Chem 31:159-164

Nascimento NC, Fett-Neto F (2010) Plant secondary metabolism and challenges in modifying its operation: an overview. Methods Mol Biol 643:1-13

Negro C, Tommasi L, Miceli A (2003) Phenolic compounds and antioxidant activity from red grape marc extracts. Bioresour Technol 87:41-44

Oszmański J (1995) Polyphenols as antioxidants in food. Przem Spoż 3:94-96 (in Polish)

Passioura J (2007) The drought environment: physical, biological and agricultural perspectives. J Exp Bot 58:113-117

Posmyk MM, Bailly C, Szafrańska K, Jasan KM, Corbineau F (2005) Antioxidant enzymes and isoflavonoids in chilled soybean [Glycine max (L.) Merr.] seedlings. J Plant Physiol 162:403-412

Rosicka-Kaczmarek J (2004) Polifenole jako naturalne antyoksydanty w żywności. Przeg Piek Cuk 6:12-16

Rudikowskaya EG, Fedorova GA, Dudareva LV, Makarova LE, Rudokovskij AV (2008) Effect of growth temperature on the composition of phenols in pea roots. Russ J Plant Physiol 55:712-715

Smirnof N (1993) Plant resistance to environmental stress. Curr Opin Biotechnol 9:214-219
Solecka D (1997) Role of phenylpropanoid compounds in plant responses to different stress factors. Acta Physiol Plant 19: $257-268$

Szafrańska K, Posmyk M, Janas KM (2002) Activity of phenylalanine ammonia lyase and soluble phenols content in two cultivars of soybean differing in sensitivity to low-temperature stress. Postępy Nauk Rolniczych 481:223-228 (in Polish)

Szwajgier D, Pielecki J, Targoński Z (2005) Antioxidant activities of cinnamic and benzoic acid derivatives. Acta Sci Pol Technol Aliment 4(2):129-142

Weidner S, Amarowicz R, Karmać M, Frączek E (2000) Changes in endogenous phenolic acids during development of Secale cereal caryopses and after dehydration treatment of unripe rye grains. Plant Physiol Biochem 38:595-602

Weidner S, Karamać M, Amarowicz R, Szypulska E, Golgowska A (2007) Changes in composition of phenolic compounds and antioxidant properties of Vitis amurensis seeds germinated under osmotic stress. Acta Physiol Plant 29:238-290

Weidner S, Karolak M, Karamać M, Kosińska A, Amarowicz R (2009a) Phenolic compounds and properties of antioxidants in grapevine roots (Vitis vinifera) under drought stress followed by regeneration. Acta Soc Bot Pol 78:97-103

Weidner S, Kordala E, Brosowska-Arendt W, Karamać M, Kosińska A, Amarowicz R (2009b) Phenolic compounds and properties of antioxidants in grapevine roots followed by recovery. Acta Soc Bot Pol 78:279-286

Weidner S, Brosowska-Arendt W, Szczechura W, Karamać M, Kosińska A, Amarowicz R (2011) Effect of osmotic stress and post-stress recovery on the content of phenolics and properties of antioxidants in germinating seeds of grapevine Vitis californica. Acta Soc Bot Pol 80:11-19

Wróbel M, Karmać M, Amarowicz R, Frączek E, Weidner S (2005) Metabolism of phenolic compounds in Vitis riparia seeds during stratification and during germination under optimal and low temperature stress conditions. Acta Physiol Plant 27(3A): $313-320$

Xiong L, Wang RG, Mao G, Koczan JM (2006) Identification of drought tolerance determinants by genetic analysis of root response to drought stress and abscisic acid. Plant Physiol 142: 1065-1074

Xu C, Zang Y, Cao L, Lu J (2010) Phenolic compounds and antioxidant properties of different grape cultivars grown in China. Food Chem 119:1557-1565

Yen GC, Chen HY (1995) Antioxidant activity of various tea extracts in relation to their antimutagenicity. J Agric Food Chem 43: $27-32$

Zadernowski R, Kozłowska H (1983) Phenolic acids in soybean and rape seed flours. Lebensm Wiss Technol 16:110-114

Zainol MK, Abd-Hamid A, Yusof S, Muse R (2003) Antioxidative activity and total phenolic compounds of leaf, root and petiole of four accessions of Centella asiatica (L.) Urban. Food Chem $81: 575-581$ 